\title{
Intranasal administration of Lignosus rhinocerotis (Cooke) Ryvarden (Tiger Milk mushroom) extract attenuates airway inflammation in murine model of allergic asthma
}

\author{
SITI AMINAH MUHAMAD ${ }^{1}$, NURUL SYAFIRA MUHAMMAD ${ }^{1}$, NURUL DINIE AYUNI ISMAIL ${ }^{1}$, \\ ROHIMAH MOHAMUD ${ }^{2}$, SABREENA SAFUAN ${ }^{1}$ and ASMA-ABDULLAH NURUL ${ }^{1}$ \\ ${ }^{1}$ School of Health Sciences; ${ }^{2}$ Department of Immunology, School of Medical Sciences, \\ Universiti Sains Malaysia, Kubang Kerian, Kelantan 16150 Malaysia
}

Received May 23, 2018; Accepted November 9, 2019

DOI: $10.3892 /$ etm.2019.7416

\begin{abstract}
Asthma is a chronic inflammatory disorder in the airways that involves the activation of cells and mediators. Lignosus rhinocerotis (Cooke) Ryvardan or Tiger Milk mushroom is a medicinal mushroom that is traditionally used to treat inflammatory diseases including asthma. In this study, the protective effects of intranasal administration of L. rhinocerotis extract (LRE) in ovalbumin (OVA)-induced airway inflammation mouse model were investigated. Mice were sensitized by intraperitoneal (i.p) injection on days 0 and 14 , followed by a daily challenge with $1 \%$ OVA from days 21 to 27. Following OVA challenge, LRE and dexamethasone were administered via intranasal and i.p. injection respectively. On day 28, the level of serum immunoglobulin $(\mathrm{Ig}) \mathrm{E}$, differential cell counts and T-helper (Th) 2 cytokines in bronchoalveolar lavage fluid (BALF) fluid, cell subset population in lung-draining lymph nodes (LNs), leukocytes infiltration and mucus production in the lungs of the animals was measured. Results demonstrated that intranasal administration of LRE significantly suppressed the level of inflammatory cell counts in BALF as well as populations of $\mathrm{CD}^{4}{ }^{+} \mathrm{T}$-cells in lung draining LNs. Apart from that, LRE also significantly reduced the level of Th2 cytokines in BALF and $\operatorname{IgE}$ in the serum in OVA-induced asthma. Histological analysis also demonstrated the amelioration of leukocytes infiltration and mucus production in the lungs. Overall, these findings demonstrated the attenuation of airway inflammation in the LRE-treated mice therefore suggesting a promising alternative for the management of allergic airway inflammation.
\end{abstract}

Correspondence to: Dr Asma-Abdullah Nurul, School of Health Sciences, Universiti Sains Malaysia, Kubang Kerian, Kelantan 16150, Malaysia

E-mail: nurulasma@usm.my

Key words: airway inflammation, allergy asthma, intranasal, Lignosus rhinocerotis

\section{Introduction}

Asthma is a common airway inflammatory disease that affects more than 300 million people worldwide $(1,2)$ and this figure is estimated to increase to 400 million by 2025 (1). The World Health Organization (WHO) placed asthma as 14th most critical disorder worldwide (1-3). Asthma is characterized by airway inflammation, airway hyper-responsiveness (AHR) and reversible airflow obstruction (4). In general, asthma is caused by $\mathrm{T}$ helper 2 (Th2)-driven inflammatory responses that induce airway eosinophilia and mucus production in the lungs. The Th2-mediated eosinophilic disease is commonly associated with atopy and is characterized by an increase expression of Th2 cytokines, including interleukin (IL)-4, IL-5 and IL-13 $(5,6)$. On the other hand, the non-Th2-subtype is characterized by the lack of Th2 inflammation and frequently associated with neutrophilic or paucigranulocytic inflammation within the airways $(5,7,8)$.

Current medications for the management of asthma include short acting $\beta$-agonists, long acting $\beta 2$-adrenergic agonists, and inhaled corticosteroids, which could alleviate the asthma attacks by relaxing the a smooth muscle in the airway. However, certain adverse effects including tachycardia, anxiety, osteoporosis, stunting of growth in children and cataract formation could be seen following prolonged used $(8,9)$. Therefore, a safer alternative for the management of asthma is needed and the use of natural products seems to be a promising approach.

Lignosus rhinocerotis (Cooke) Ryvarden (Tiger Milk mushroom) or locally known as "cendawan susu rimau" has a long history of use as natural remedies for various diseases by the local and indigenous communities in Malaysia (10). A previous study had demonstrated that $L$. rhinocerotis sclerotia exhibited anti-proliferative (11) and immunomodulatory properties (12). Furthermore, Lee et al (10) reported that sclerotial powder of L. rhinocerotis also demonstrated anti-inflammatory properties in carrageenan-induced paw oedema model in rats. The first report on the anti-asthmatic properties of L. rhinocerotis was reported by Johnathan et al (13) which demonstrated that the oral administration of $L$. rhinocerotis extract significantly reduced the level of Th2 cytokines in the bronchoalveolar lavage fluid (BALF), IgE level in the serum and attenuated the 
number of leukocyte infiltrating into the lung tissues. In the present study, the effectiveness of intranasal administration of hot water extract of sclerotial powder of the L. rhinocerotis in the ovalbumin-induced allergic asthma mouse model was examined.

\section{Materials and methods}

Preparation of L. rhinocerotis by hot water extraction. Sclerotia of L. rhinocerotis cultivar TM02 was obtained from Ligno Biotech Sdn. Bhd. (Selangor, Malaysia) in dried powdered form. To prepare the extract, $50 \mathrm{~g}$ of L. rhinocerotis sclerotium powder was immersed in $600 \mathrm{ml}$ of purified distilled water and subjected to hot water extraction using a Soxhlet extraction machine (14) for 5 days. The extract was then subjected to a rotary evaporator (Ilshin BioBase, Gyeonggi-do, South Korea) for freeze-drying into lyophilized powder form. A total of $\sim 5 \mathrm{~g}$ of L. rhinocerotis extract (LRE) could be obtained from $50 \mathrm{~g}$ of sclerotial powder.

Animals. Ethical approval was obtained from the Animal Ethics Committee of the Universiti Science Malaysia (Kelantan, Malaysia; Animal Ethics Approval/2016/799). A total of 36 female Balb/c mice, aged 6-8 weeks (weight, 20-30 g), were used in this experiment. The mice $(\mathrm{n}=36)$ were maintained in polystyrene cages in an air-controlled room at $25 \pm 1^{\circ} \mathrm{C}$ with a $12 \mathrm{~h} \mathrm{light/dark}$ cycle and they were given food pellet and water ad libitum. The animals were acclimatized to the experimental environment prior to the commencement of the study.

Sensitization, challenge and treatment. The mice were randomly divided into six groups with six mice per group $(n=6)$ : i) Normal group (as negative control), ii) sensitization plus OVA challenge (as positive OVA control), iii) sensitization plus OVA challenge/intranasal LRE (125 mg/kg per body weight), iv) sensitization plus OVA challenge/intranasal LRE (250 mg/kg per body weight), v) sensitization plus OVA challenge/intranasal LRE (500 mg/kg per body weight) and vi) sensitization plus OVA challenge/intraperitoneal (i.p) dexamethasone ( $3 \mathrm{mg} / \mathrm{kg}$ per body weight; Nacalai Tesque, Inc., Kyoto, Japan). On day 0 and day 14, the mice were sensitized with $20 \mu \mathrm{g}$ ovalbumin (OVA) and $4 \mathrm{mg}$ aluminium hydroxide (alum) (both Nacalai Tesque, Inc.) in $100 \mu$ l PBS (15). Starting on day 21 , the mice were challenged with $1 \%$ OVA aerosol for $20 \mathrm{~min} /$ day for 7 consecutive days by using an ultrasonic nebulizer (Mabist mist; Mabist DMI Healthcare, Illinois, CA, USA) as described in Fig. 1. The animals in the normal group were sensitized and challenged with normal saline at the same time intervals. Finally, $24 \mathrm{~h}$ following the final challenge, the mice were euthanized with i.p pentobarbital $(200 \mathrm{mg} / \mathrm{kg})$ and samples were collected; bronchoalveolar lavage fluid (BALF) for inflammatory cell counts and cytokine determination, blood $(0.5 \mathrm{ml} / \mathrm{mice})$ for total immunoglobulin (Ig) E level, lung draining lymph nodes (LN) for cell subset populations and lungs for histopathological analysis.

Eosinophil and inflammatory cell counts. Following sacrifice, BALF was obtained using an endotracheal tube by instilling and aspirating from the trachea with $0.4 \mathrm{ml}$ of $1 \%$ fetal calf serum (Capricon Scientific GmbH, Ebsdorfergrund, Germany) in phosphate buffer saline (PBS) for three times. BALF were centrifuged at $\left(350 \mathrm{x}\right.$ g for $5 \mathrm{~min}$ at $\left.4^{\circ} \mathrm{C}\right)$ and the cell pellet was re-suspended with $1 \mathrm{XPBS}$ (50-200 $\mu 1$, depending on cell numbers) and centrifuged $\left(350 \times \mathrm{g}\right.$ for $5 \mathrm{~min}$ at $\left.4^{\circ} \mathrm{C}\right)$ at room temperature. Slides for differential cell counts were air dried, fixed with methanol for 1-2 min and stained with Giemsa-stain for 8 min (Merck KGaA, Darmstadt, Germany) at room temperature. The absolute numbers of each cell types (neutrophil, eosinophil and lymphocyte) were identified using a hemocytometer, depending on the standard morphology criteria of cells using a fluorescence microscope at x1,000 magnification and under an oil immersion lens.

Cytokines quantification and IgE determination. The total IgE level (BD Bioscience, San Jose, CA, USA) in serum and Th2 cells secreting IL-4 (cat. no. 431105), IL-5 (catalog no. 431205; both Biolegend, Inc., San Diego, CA, USA) and IL-13 (cat. no. 900-K207; Peprotech, Inc., Rocky Hill, NJ, USA) in BALF were measured using ELISA kits according to the manufacturer's protocol.

Cell surface staining. All fluorochrome-labelled monoclonal antibodies used in surface staining were titrated prior to use in order to determine the optimal antibody dilution for the surface marker detection by flow cytometry (data not shown). Lung draining lymph nodes (LN) cells were stained and analyzed with the combinations of the monoclonal antibodies: Cluster of differentiation (CD)3-PerCP-Cy ${ }^{\mathrm{TM}} 5.5$ rat anti-mouse (1:200; cat. no. 561609) and CD4-fluorescein isothiocyanate (FITC; 1:200; cat. no. 553650; both BD Pharmingen ${ }^{\mathrm{TM}}$; BD Biosciences). The single cell suspensions were centrifuged (300 x g for $10 \mathrm{~min}$ at $4^{\circ} \mathrm{C}$ ) and re-suspended in FACS staining buffer [PBS $+0.5 \%$ bovine serum albumin (Thermo Fisher Scientific, Inc. Waltham, MA, USA) $+0.05 \%$ sodium azide]. Following staining, the samples were scanned using a flow cytometer (BD FACS Canto II $^{\mathrm{TM}}$ ) and analyzed using FCS Express 6 Flow Research Edition (De Novo Software, Glendale, CA, USA).

Histopathological analysis. Following BALF collection, mice lungs were perfused with PBS solution, removed and fixed in $10 \%$ neutral-buffered formalin overnight at room temperature. A conventional tissue processing method was applied in which the lung tissues were embedded in paraffin and cut into 5- $\mu \mathrm{m}$ thickness sections, followed by Harris haematoxylin staining for $20 \mathrm{~min}$ and eosin staining for $3 \mathrm{~min}$ at room temperature (both Sigma-Aldrich; Merck KGaA, Dramstradt, Germany) for analysis of leukocyte infiltration. Lungs were stained with periodic acid-schiff staining (Sigma-Aldrich; Merck $\mathrm{KGaA}$ ) for $20 \mathrm{~min}$ at room temperature for the analysis of goblet cell hyperplasia. The tissue was subsequently mounted and cover-slipped with di-n-butyl phthalate in xylene (DPX) mounting medium. Morphometric histological analyses were performed under a fluorescence microscope (Olympus Corporation, Tokyo, Japan). The cell infiltration intensity at the peribronchiolar and the perivascular region was graded on the hot spot area using the following scores; 0: No inflammatory cells, 1: A few inflammatory cells, 2: A ring of inflammatory cells (1 cell layer deep), 3: A ring of inflammation cells (2-4 


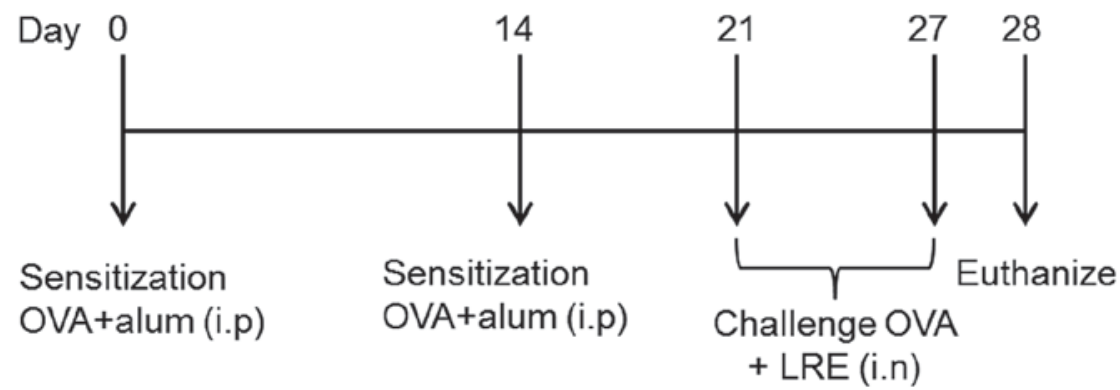

Figure 1. Experimental protocol of sensitization, OVA challenge and treatment in airway inflammation asthma model. OVA, ovalbumin; alum, aluminium hydroxide; i.p., intraperitoneal; i.n., intranasal; LRE, Lignosus rhinocerotis extract.

cells layer deep), 4: A ring of inflammation cells (>4 cells layer deep). For the analysis of mucus, the scoring was done according to the following method; 0 : No goblet cells, $1:<25 \%$ of epithelium, 2: $25-50 \%$ of epithelium, 3: 50-75\% of epithelium, $4:>75 \%$ of epithelium $(16,17)$.

Statistical analysis. Data was expressed as mean \pm standard error of the mean and experiments were performed in triplicate. Statistical significance was determined by one-way analysis of variance, followed by Bonferroni's post hoc test to determine the significant difference between the treatment groups by using GraphPad Prism software version 6.01 (Graphpad Software, Inc., La Jolla, CA, USA). P $<0.05$ was considered to indicate a statistically significant difference.

\section{Results}

Eosinophil and inflammatory cell counts. The number of eosinophils, neutrophils and lymphocytes present in BALF from the normal group were $9.0 \pm 1.64,13.0 \pm 2.15,18.3 \pm$ and 3.18 respectively. Sensitization and challenge with OVA stimulated a significant increase of the eosinophil and neutrophil counts ( $36.17 \pm 1.74$ and $26.83 \pm 2.24$ respectively) compared with the normal group, indicating a satisfactory level of sensitization towards the allergens. However, OVA sensitization and challenged demonstrated a reduction in lymphocyte count with $7.17 \pm 1.92$ compared with the normal group. LRE treatment $(125,250$ and $500 \mathrm{mg} / \mathrm{kg})$ and dexamethasone significantly attenuated the eosinophil and neutrophil infiltration, reaching its highest level at $500 \mathrm{mg} / \mathrm{kg}(\mathrm{P}<0.01$; Fig. 2). However, the lymphocyte counts significantly increased $(\mathrm{P}<0.01)$ following treatment with $500 \mathrm{mg} / \mathrm{kg}$ of LRE compared with the OVA group.

$R E$ suppresses the level of Th2 cytokine and serum immunoglobulin E (IgE) production. Results indicated that LRE significantly $(\mathrm{P}<0.01)$ attenuated the level of IL-4 and IL-5 at $500 \mathrm{mg} / \mathrm{kg}$ compared with the OVA group (Fig. 3A and B) and notably, dexamethasone significantly reduced IL-4 level in BALF $(\mathrm{P}<0.05$; Fig. 3A). In contrast, LRE $(250 \mathrm{mg} / \mathrm{kg})$ significantly restored the IL-13 level compared with the OVA-challenged group $(\mathrm{P}<0.01$; Fig. $3 \mathrm{C})$. These findings imply that LRE is capable of modifying the Th2 predominant immune activity in OVA-induced mouse model of asthma. Therefore, to further assess whether LRE could modify the OVA-specific Th2 response, the serum IgE level was determined using ELISAs.

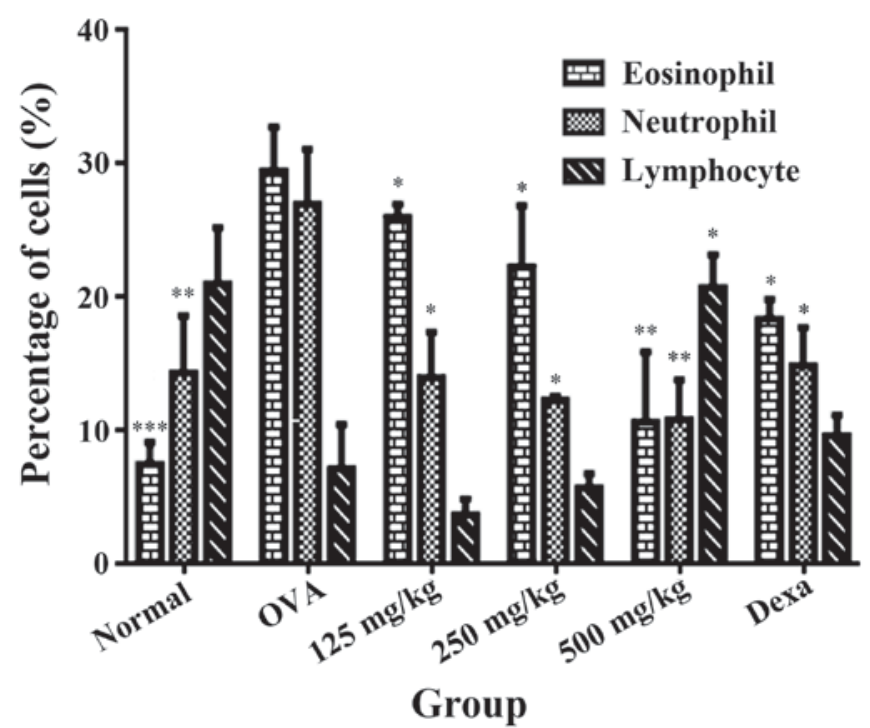

Figure 2. LRE inhibits inflammatory cell influx in BALF. Effects of intranasal administration of $\operatorname{LRE}(125,250$ and $500 \mathrm{mg} / \mathrm{kg})$ and administration of dexamethasone (i.p; $3 \mathrm{mg} / \mathrm{kg}$ ) on eosinophils, neutrophils and lymphocytes in BALF. Mice were sensitized on day 0 and 14 with OVA $(200 \mathrm{mg} / \mathrm{ml})$ prepared in alum and challenged with $1 \%$ OVA. Normal group was administered (i.p) and challenged with saline instead of OVA. Values are expressed as the mean \pm standard deviation ( $\mathrm{n}=6 /$ group). ${ }^{*} \mathrm{P}<0.05,{ }^{* *} \mathrm{P}<0.01$ and ${ }^{* * * *} \mathrm{P}<0.001$ compared with the OVA group. BALF, bronchoalveolar lavage fluid; OVA, ovalbumin; alum, aluminium hydroxide; i.p., intraperitoneal; LRE, Lignosus rhinocerotis extract.

Taking this into account, the concentration of $\operatorname{IgE}$ present in the blood serum of normal group was $720.8 \pm 15.66 \mathrm{ng} / \mathrm{ml}$, whereas sensitization and OVA challenge promoted a slight increase to $764.6 \pm 18.74 \mathrm{ng} / \mathrm{ml}$ (Fig. 3D). Dexamethasone however did not demonstrate any significant change $(\mathrm{P}>0.05)$ compared with the OVA-induced group.

The effects of LRE on helper T cell populations. Fig. 4A and B presents the isolation of cells from lung-draining LN. The cells were double-stained with CD3-PerCP and CD4-FITC and analyzed by flow cytometry. The percentage of $\mathrm{CD}^{+} \mathrm{CD}^{+}$ cells in the normal group was $8.74 \pm 0.87 \%$. On the other hand, the stimulation with OVA increased the percentage of the cells by $68.84 \pm 4.82 \%$ (Fig. 4B). Treatment with LRE indicated the reduction of helper T-lymphocytes percentage at all dosages and reached its greater reduction at $125 \mathrm{mg} / \mathrm{kg}(\mathrm{P}<0.001)$. Similarly, dexamethasone significantly attenuated the $\mathrm{CD} 3{ }^{+} \mathrm{CD} 4{ }^{+}$cell population $(\mathrm{P}<0.001)$ compared with the OVA group. 

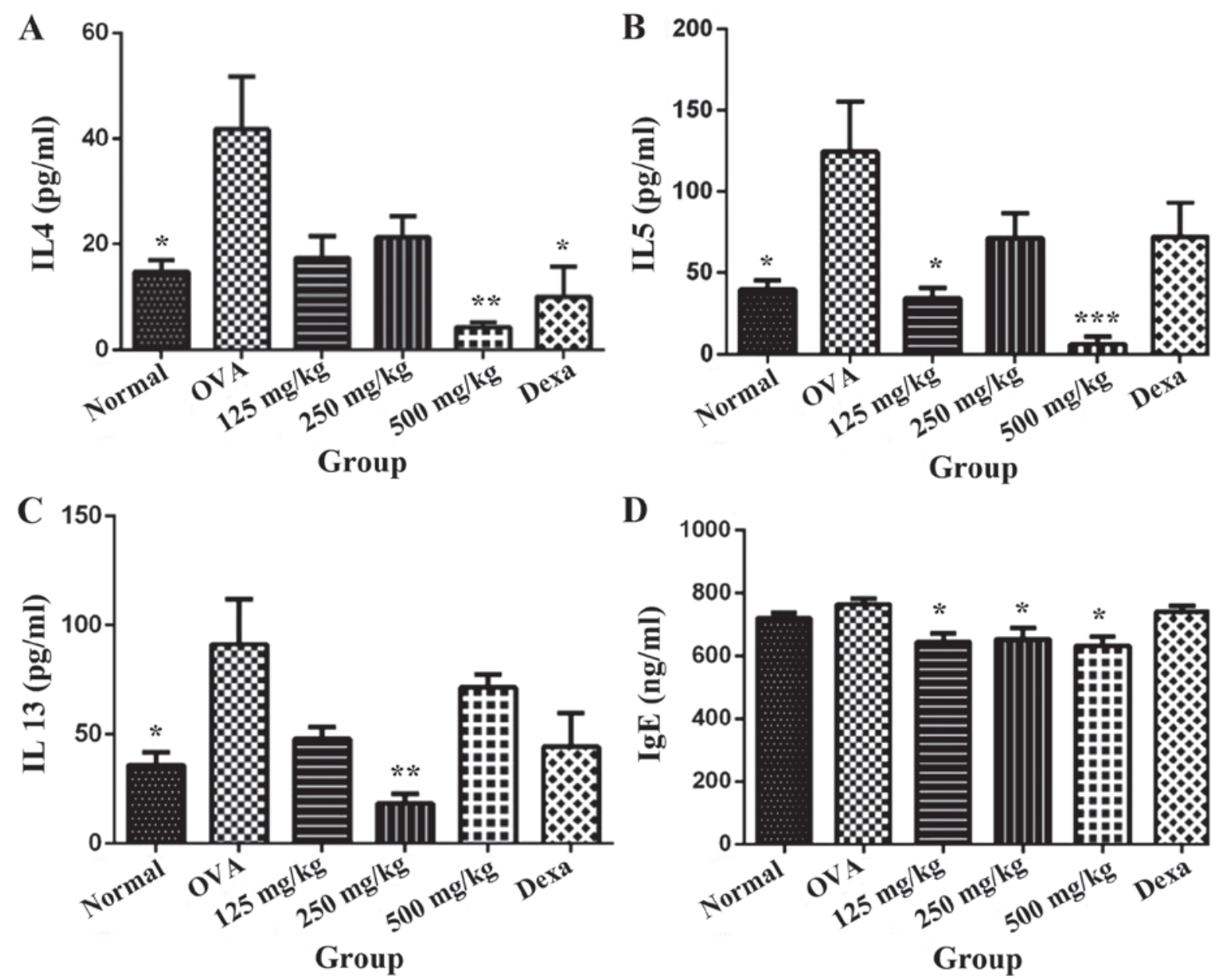

Figure 3. LRE inhibits the production of helper T2 cell-specific cytokines in BALF and IgE in blood serum. Effects of intranasal administration of LRE $(125,250$ and $500 \mathrm{mg} / \mathrm{kg}$ ) and administration of Dexa (i.p; $3 \mathrm{mg} / \mathrm{kg}$ ) on the level of (A) IL-4, (B) IL-5, (C) IL-13 in BALF and (D) IgE in serum are presented. Mice were sensitized on day 0 and 14 with (OVA; $200 \mathrm{mg} / \mathrm{ml}$ ) prepared in alum and challenged with $1 \%$ OVA. The normal group was administered (i.p) and challenged with saline instead of OVA. Values are expressed as the mean \pm standard deviation ( $\mathrm{n}=6 /$ group). ${ }^{*} \mathrm{P}<0.05,{ }^{* * *} \mathrm{P}<0.01$ and ${ }^{* * *} \mathrm{P}<0.001$ indicates significant different from OVA. BALF, bronchoalveolar lavage fluid; OVA, ovalbumin; alum, aluminium hydroxide; i.p., intraperitoneal; Dexa, dexamethasone; LRE, Lignosus rhinocerotis extract; Ig, immunoglobulin; IL, interleukin.

LRE suppresses leukocytes infiltration and mucus production in lungs. LRE (250 and $500 \mathrm{mg} / \mathrm{kg}$ ) and dexamethasone treatment significantly diminished the eosinophil-rich leukocyte infiltration compared with the OVA challenge group $(\mathrm{P}<0.0001$; Fig. 5), while mucus hypersecretion in OVA-induced mice was significantly attenuated by LRE treatment at $500 \mathrm{mg} / \mathrm{kg}$ $(\mathrm{P}<0.0001)$ and dexamethasone $(\mathrm{P}<0.01 ;$ Fig. 6).

\section{Discussion}

Asthma is a complex inflammatory airway disease that results from the activation of various inflammatory and structural cells, leading to airway inflammation, airway obstruction, mucus hypersecretion and acute hyperresponsiveness (18). The anti-asthmatic activity of L rhinocerotis was investigated through a mouse model induced by OVA sensitization. Generally, animals demonstrated similar hallmarks to acute human allergic asthma characterized by pathophysiological alterations in airways, mucus secretion, production of allergen specific IgE and the increase of Th2 cytokines level (19). The mechanism of asthma is not fully elucidated, but in general it occurs due to an imbalance in Th1/Th2 components and other factors associated with disease occurrence. It is characterized by the increasing level of Th 2 cytokines (IL-4, IL-5 and IL-13) and the reduction in Th1 cytokine levels (interferon-gand IL-2) $(20,21)$.

A mouse model of asthma was established using OVA by sensitization and challenge to mimic the pathological alterations in asthma patients. Generally, following allergens exposure, T cells will be activated by the dendritic cells, which lead to Th2 response, resulting in the production of cytokines (IL-4, IL-5 and IL-13). CD4+ cells secrete IL-4 and IL-13, that are involved in the production of IgE by mast cells, transforming growth factor $\beta$ (TGF- $\beta$ ) and causing direct effects on fibroblasts, epithelial cells, and airway smooth muscle that leads to airway narrowing, AHR and structural changes (22). Furthermore, IL-5 is crucial in development and activation of eosinophils that directly influence the airway narrowing through the release of TGF- $\beta$, IL- 4 , and IL- 13 . In the present study, Balb/c mice were used as a model for induction of airway inflammation as they could develop an efficient Th2-biased immunological response $(23,24)$. In this study, the animals (except for normal group) were sensitized twice on day 0 and day 14 , to ensure the eosinophils did not 
A
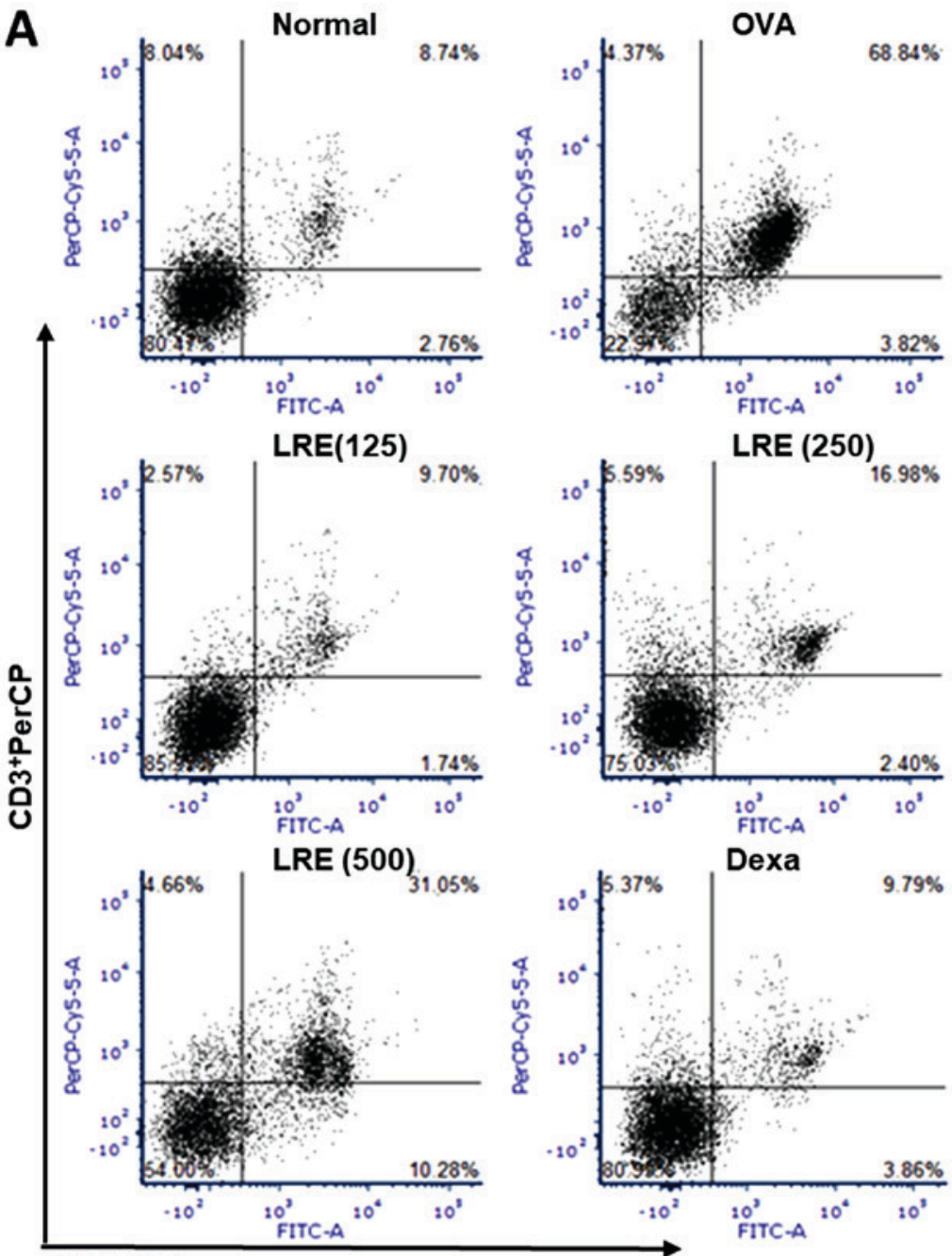

CD4+FITC

B

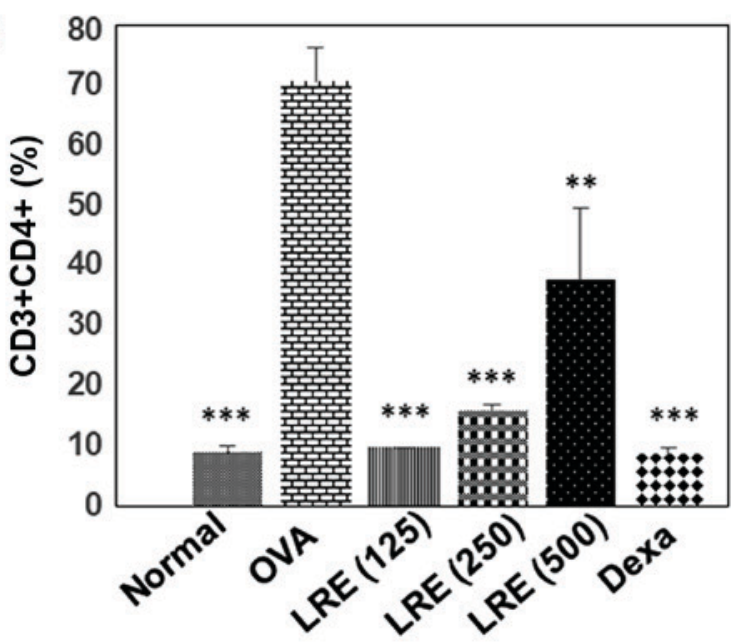

Figure 4. Characterization of CD4 ${ }^{+}$T-lymphocyte populations in lung-draining LN. (A) Dot-plot representatives of lung-draining LN stained with surface $\mathrm{T}$ cell markers; $\mathrm{CD}^{+}-\mathrm{PerCP}$ and $\mathrm{CD}^{+}$-FITC. (B) OVA-sensitization increases $\mathrm{CD}^{+} \mathrm{CD}^{+}$cells while treatment with LRE reduces the percentage of helper T-lymphocytes indicating alleviation of inflammation. Mice were sensitized on day 0 and 14 with (OVA; $200 \mathrm{mg} / \mathrm{ml})$ prepared in aluminium hydroxide and challenged with $1 \%$ OVA. The normal group was administered (intraperitoneally) and challenged with saline instead of OVA. Values are expressed as the mean \pm standard deviation ( $\mathrm{n}=6 /$ group). ${ }^{* *} \mathrm{P}<0.01$ and ${ }^{* * * *} \mathrm{P}<0.001$, vs. OVA. $\mathrm{LN}$, lymph node; OVA, ovalbumin; CD, cluster of differentiation; FITC, fluorescein isothiocyanate; LRE, Lignosus rhinocerotis extract; Dexa, dexamethasone.

return to the baseline level and to prevent the development of tolerance (25). Dexamethasone was used as positive control because it is an effective inhibitor of airway inflammation and airway remodeling in animal models (26).
Lymphocytes coordinate the immune response and serve a central role in cell mediated immunity. Lymphocyte subsets may include helper $\mathrm{T}$ cells $\left(\mathrm{CD} 4^{+} \mathrm{T}\right.$-cells), cytotoxic $\mathrm{T}$ cells (CD8 ${ }^{+} \mathrm{T}$-cells), memory $\mathrm{T}$ cells and regulatory $\mathrm{T}$ cells (Treg 

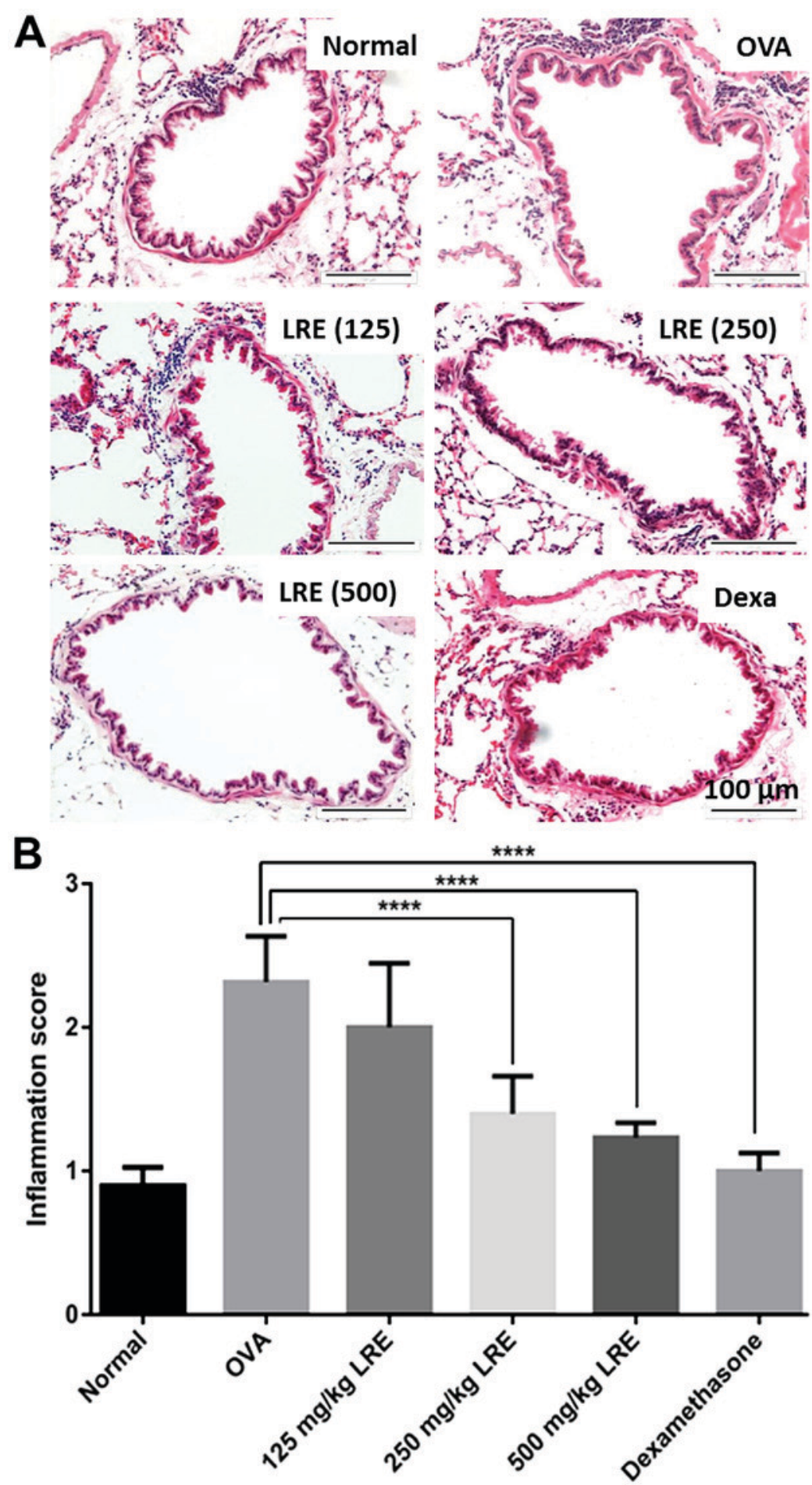

Figure 5. Effects of LRE on inflammatory leukocyte infiltration in the peribronchiolar and perivascular regions of the lungs. (A) Representative photomicrographs demonstrating hematoxylin and eosin staining at magnification x40. (B) Quantitative analysis of the inflammation score with a subjective scale of $0-4$ to represent leukocyte infiltration in the lung. Values are expressed as the mean \pm standard deviation ( $\mathrm{n}=6$ per group). ${ }^{* * * * *} \mathrm{P}<0.0001 \mathrm{vs}$. OVA. LRE, Lignosus rhinocerotis extract; Dexa, dexamethasone; OVA, ovalbumin.

cells) (27). Flow cy tometry is used to provide absolute counts, percentages and/or ratios of these lymphocyte subsets (27). $\mathrm{CD} 4^{+} \mathrm{T}$ cells become activated and proliferate rapidly upon encounter with antigens, secreting cytokines that sends signals and maintain an active immune response (27). The $\mathrm{CD} 4^{+}$count provides a picture of immune system competence, with higher counts typically signifying healthier immune systems. Activation of T cells could influence the severity of asthma, including the degree of airway narrowing and bronchial eosinophil response (28). Apart from the involvement of Th1 and Th2 cells in the pathogenesis of asthma, it was reported that Treg cells also serve a crucial role in asthma $(29,30)$. Foxp3 $3^{+}$Treg cells are a distinct subset of $\mathrm{CD} 4^{+} \mathrm{T}$ cells which can suppress effector $\mathrm{CD} 4^{+} \mathrm{T}$ cells responses (31) and have been demonstrated to serve a crucial role in allergic diseases, including asthma $(29,31,32)$. Foxp $3^{+}$ 

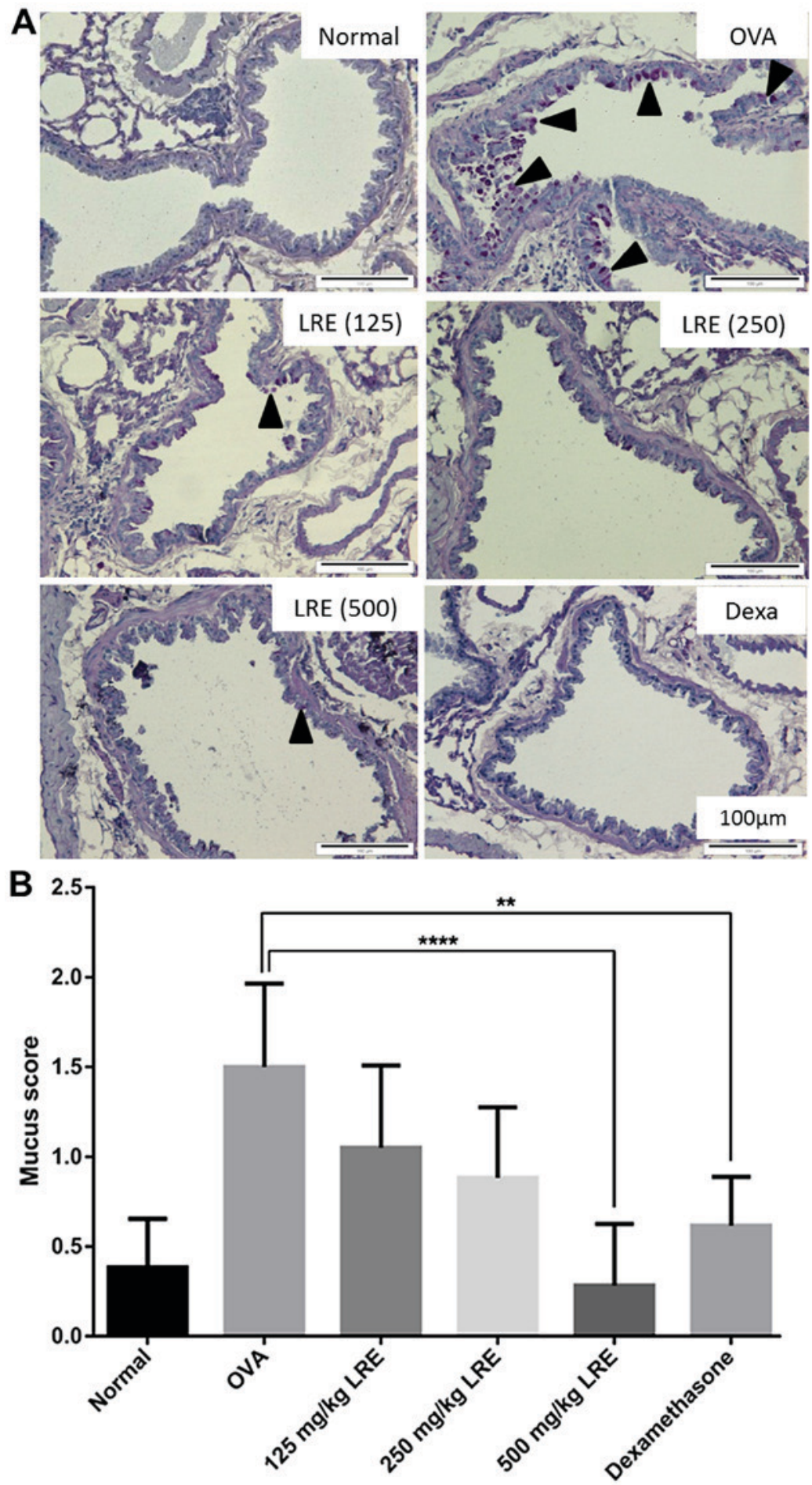

Figure 6. Effects of LRE on mucus production in lungs. (A) Representative photomicrographs exhibiting Periodic-acid Schiff staining at magnification x40. (B) Quantitative analysis of mucus secretion with a subjective scale of 0-4. Arrowheads indicate the presence of goblet cell hyperplasia and mucus around the bronchiole. Values are expressed as the mean \pm standard deviation $\left(\mathrm{n}=6\right.$ per group) ${ }^{* * *} \mathrm{P}<0.01$ and ${ }^{* * * * *} \mathrm{P}<0.0001$ vs. OVA group. LRE, Lignosus rhinocerotis extract; Dexa, dexamethasone; OVA, ovalbumin.

Treg cells can attenuate the Th2 and Th17 cell-mediated inflammation and prevent airway inflammation as well as bronchial hyper-responsiveness in asthmatic patients and in animal models $(32,33)$. In the current study, OVA-sensitized and -challenged animals had $C D 4^{+} \mathrm{T}$ cells activated and therefore the inflammatory responses were induced, the cytokines level was altered and the production of leukocyte infiltration in the lungs regions increased. Notably, intranasal administration of LRE modulated the percentages of $\mathrm{CD}_{3}{ }^{+} \mathrm{CD} 4^{+}$cells; similar observation could be observed in dexamethasone treated-animals.

Allergic asthma is associated with eosinophilic inflammation in the airways (34). Generally, eosinophils are developed and distinguished under the influence of IL-5, which enters the site of inflammation or infection (35). Activation of eosinophils leads to the release of pro-inflammatory 
mediators including major basic protein, cationic protein, leukotriene $\mathrm{C} 4$, prostaglandin E2 and thromboxane. They are also capable of synthesizing and releasing interleukins (IL-3, IL-4, IL-5, IL-8, IL-10, 1L-12 and IL-13), chemokines (CCL5/RANTES and CCL11/eotaxin-1), tumor necrosis factor- $\alpha$ and TGF- $\beta$ (36). A number of studies have pointed out that the neutralization of IL-5 could diminish pulmonary eosinophilia in response to allergens $(26,35)$. Furthermore, neutrophils are known to be one of the first inflammatory cells to be recruited to the site of allergens exposure. It produces metalloproteases and elastase, which are vital in vascular permeability, mucus secretion and bronchoconstriction (37). Nabe et al (38), demonstrated an increase of neutrophils level in the airways of mouse OVA-challenged model. This study indicated that OVA-sensitized and -challenged group escalated the number of eosinophil and neutrophil cells and these cells were attenuated with the treatment of LRE and dexamethasone. Furthermore, the suppression of the inflammatory cells in BALF was also validated by lung tissue histology.

In allergen-sensitized model with atopic asthma, re-exposure to the allergen leads to IgE mediated inflammatory cascade in the airways. Airway resident cells (e.g., mast cells and macrophages), newly mobilized immune cells (e.g., eosinophil and neutrophil) and epithelial cells are vital in this inflammatory cascade (39). In allergic inflammation, there seems to be an imbalance between Th1/Th2 cytokines with dominance towards Th2 cytokines (IL-4, IL-5 and IL-13) (40). IL-4 is known to be the main cytokine involved in the pathogenesis of the allergic response. It has vital functions in airway remodeling by stimulating the mucus production and fibroblasts, inducing B-cells to produce $\operatorname{IgE}$ and upregulation of molecules that enable the migration of leukocytes to the airways (4). It has been extensively reported that IL-5 is reliable in an eosinophil's development in the bone marrow and their recruitment into interstitial mucosa and lungs due to chemokine's production. Furthermore, IL-13 is reported to be the most effective inducer of eotaxin expression by airway epithelial cells on the respiratory tract and promotes mucus production in lung tissues (41). IL-13 however, is also reported to have independent roles from IL-4, IL-5, eosinophil and IgE (42). IL-13 has been demonstrated to independently elicit a number of key pathological features of asthma including migration and upregulation of adhesion molecules, goblet cell hyperplasia and stimulation of airway hyperresponsiveness (43). It is crucial to know that there are few therapies for asthma that are targeting Th2 cytokines, for examples recombinant soluble IL-4 receptor antagonist (Altrakincept ${ }^{\circledR}$, Aerovance Incorporation; Pitrakinra and Amgen), IL- 4 receptor $\alpha$-chain antibody (Dupilumab $^{\circledR}$, Regeneron Pharmaceuticals), IL-13 blockade (Lebrikizumab ${ }^{\circledR}$, Genentech) and antibody to the IL-5 receptor (Benralizumab ${ }^{\circledR}$, AstraZeneca/MedImmune) $(6,44,45)$.

According to Holgate (46), an increase level of IgE in asthmatic patients is strongly associated with the increase of Th2 cytokines, therefore worsening the clinical symptoms of the disease. IL-4 directly engages in the differentiation of B lymphocytes towards IgE synthesis. This highlights the vital function of receptor (FceRI) that is present in mast cells, basophils and dendritic cells that induce cellular activation, inflammation, and production of mediators including Th2 cytokines $(41,47)$. In the present study, LRE $(125,250$ and $500 \mathrm{mg} / \mathrm{kg})$ reduced the $\operatorname{IgE}$ level compared with the OVA group. Upon allergen exposure, the IgE-coated mast cells identify the allergen deposited prior to degranulating. Activation of mast cells leads to the production of histamine, cysteinyl-leukotrienes and prostaglandin D2, which in turn lead to the additional recruitment of Th2 cells, eosinophils and basophils to the tissue (48). This process promotes immediate bronchoconstriction, airway inflammation and airway construction, congestion and systemic reflexes (49).

Histological examination was performed on the lung tissues to analyze the effect of LRE on the histological features of asthma and to examine the structural changes or pathological responses in the lung tissue. The development of asthma can be characterized by the mobilization of migrated cells, especially eosinophils and neutrophils into the peribronchiolar and perivascular regions (50). In the present study, histopathological analysis of lungs tissue sections demonstrated that the sensitization and OVA challenge promoted inflammation indicated by the presence of leukocyte infiltration and markedly increased goblet cell hyperplasia and mucus hypersecretion in the bronchi compared with the normal group. This study demonstrated that LRE could effectively inhibit the inflammatory response in the lung of the OVA-challenged mice by reducing the number of leukocytes infiltration and mucus production. A study by Jin et al (51) stated that Astragalus membranaceus remarkably attenuated the airway inflammation in OVA-sensitized animals. Similarly, ethanolic extract from Erythrina mulungu Benth significantly decreased the cellular inflammatory infiltration in the lung tissue (52). These results were in agreement with the previous study which demonstrated that oral administration of $L$. rhinocerotis effectively reduced the leukocyte migration in the lung tissues (13). In particular, studies on transbronchial biopsies of patients with nocturnal asthma demonstrated that a decrease in lung functions was correlated with the increasing number of $\mathrm{CD}^{+} \mathrm{T}$ lymphocytes and eosinophils in the alveolar walls (53-55).

In this study the attenuation of asthma-associated parameters i.e. Th2 cytokines, IgE, percentage of $\mathrm{CD}^{+} \mathrm{T}$ cell population as well as leukocytes and mucus infiltration in the lungs were demonstrated. Intranasal administration of LRE exhibited protective effects against OVA-induced asthma; the results of the present study suggest the potential of L. rhinocerotis as an alternative for the management of allergic airway inflammation.

\section{Acknowledgements}

The authors would like to thank Mr. Jamaruddin Mat Asan from the Immunology Department, School of Medical Sciences and staff from Animal Research and Service Centre USM for their assistance throughout the study.

\section{Funding}

The present study was funded by the Research University Grants (grant no: 1001/PPSK/813065 and 1001/PPSK/812180). 


\section{Availability of data and materials}

All data generated or analysed during the present study are included in this published article.

\section{Authors' contributions}

SAM, NSM and NDAI performed the experiments and manuscript preparation. SS was involved in the analysis and validation of histology slides. RM intranasally administered of LRE into the animals. AAN was involved in planning of and supervising the project. All authors discussed the results and contributed to the final manuscript.

\section{Ethics approval and consent to participate}

The experimental protocols and animal care were approved by the Animal Ethics Committee, Universiti Sains Malaysia (Animal Ethics Approval/2016/(799).

\section{Patient consent for publication}

Not applicable.

\section{Competing interests}

The authors declare that they have no competing interests.

\section{References}

1. Network GA: The global asthma report 2014. Auckland, New Zealand, Global Asthma Network, 2014, 2017.

2. Murray CJ, Vos T, Lozano R, Naghavi M, Flaxman AD, Michaud C, Ezzati M, Shibuya K, Salomon JA, Abdallah S, et al: Disability-adjusted life years (DALYs) for 291 diseases and injuries in 21 regions, 1990-2010: A systematic analysis for the Global Burden of disease study 2010. Lancet 380: 2197-2223, 2012.

3. To T, Stanojevic S, Moores G, Gershon AS, Bateman ED, Cruz AA and Boulet LP: Global asthma prevalence in adults: Findings from the cross-sectional world health survey. BMC Public Health 12: 204, 2012.

4. Steinke JW and Borish L: Th2 cytokines and asthma. Interleukin-4: Its role in the pathogenesis of asthma, and targeting it for asthma treatment with interleukin-4 receptor antagonists. Respi Res 2: 66-70, 2001.

5. Anto JM, Bousquet J, Akdis M, Auffray C, Keil T, Momas I, Postma DS, Valenta R, Wickman M, Cambon-Thomsen A, et al: Mechanisms of the development of allergy (MeDALL): Introducing novel concepts in allergy phenotypes. J Allergy Clin Immunol 139: 388-399, 2017.

6. Fajt ML and Wenzel SE: Development of new therapies for severe asthma. Allergy Asthma Immunol Res 9: 3-14, 2017.

7. Kaur J, Alvarez A, Hanna HW, Krishnan AC, Senador D, Machado TM, Altamimi YH, Lovelace AT, Dombrowski MD, Spranger MD, et al: Interaction between the muscle metaboreflex and the arterial baroreflex in control of arterial pressure and skeletal muscle blood flow. Am J Physiol Heart Circ Physiol 311: H1268-H1276, 2016.

8. Newnham JP: Is prenatal glucocorticoid administration another origin of adult disease? Clin Exp Pharmacol Physiol 28: 957-961, 2001.

9. Barnes PJ: Reduced histone deacetylase in COPD: Clinical implications. Chest 129: 151-155, 2006.

10. Lee SS, Tan NH, Fung SY, Sim SM, Tan CS and Ng ST: Anti-inflammatory effect of the sclerotium of Lignosus rhinocerotis (Cooke) Ryvarden, the Tiger Milk mushroom. BMC Complement and Altern Med 14: 359, 2014.

11. Yap YH, Tan N, Fung S, Aziz AA, Tan C and Ng S: Nutrient composition, antioxidant properties, and anti-proliferative activity of Lignosus rhinocerus Cooke sclerotium. J Sci Food Agric 93: 2945-2952, 2013.
12. Wong $\mathrm{KH}$, Lai CK and Cheung PC: Immunomodulatory activities of mushroom sclerotial polysaccharides. Food Hydrocol 25: 150-158, 2011.

13. Johnathan M, Gan SH, Ezumi MF, Faezahtul AH and Nurul AA: Phytochemical profiles and inhibitory effects of Tiger Milk mushroom (Lignosus rhinocerus) extract on ovalbumin-induced airway inflammation in a rodent model of asthma. BMC Complement Altern Med 16: 167, 2016.

14. Jonathan G, Loveth K and Elijah O: Antagonistic effect of extracts of some Nigerian higher fungi against selected pathogenic microorganisms. Am Eur J Agric Environ Sci 2: 364-368, 2007.

15. Jeon WY, Shin IS, Shin HK, Jin SE and Lee MY: Aqueous extract of gumiganghwal-tang, a traditional herbal medicine, reduces pulmonary fibrosis by transforming growth Factor- $\beta 1 / \mathrm{Smad}$ signaling pathway in murine model of chronic Asthma. PLoS One 11: e0164833, 2016.

16. Myou S, Leff AR, Myo S, Boetticher E, Tong J, Meliton AY, Liu J, Munoz NM and Zhu X: Blockade of inflammation and airway hyperresponsiveness in immune-sensitized mice by dominant-negative phosphoinositide 3-kinase-TAT. J Exp Med 198: 1573-1582, 2003.

17. Lee MY, Ahn KS, Kwon OK, Kim MJ, Kim MK, Lee IY, Oh SR and Lee HK: Anti-inflammatory and anti-allergic effects of kefir in a mouse asthma model. Immunobiol 212: 647-654, 2007.

18. Prado CM, Leick-Maldonado EA, Kasahara DI, Capelozzi VL, Martins MA and Tibério IF: Effects of acute and chronic nitric oxide inhibition in an experimental model of chronic pulmonary allergic inflammation in guinea pigs. American Am J Physiol Lung Cell Mol Physiol 289: L677-L683, 2005.

19. Kumar RK, Herbert C and Foster PS: The 'classical' ovalbumin challenge model of asthma in mice. Curr Drug Targets 9: 485-494, 2008.

20. Kang JH, Kim BS, Uhm TG, Lee SH, Lee GR, Park CS and Chung IY: Gamma-secretase inhibitor reduces allergic pulmonary inflammation by modulating Th1 and Th2 responses. Am J Respi Critical Care Med 179: 875-882, 2009.

21. Zhou M, Cui ZL, Guo XJ, Ren LP, Yang M, Fan ZW, Han RC and $\mathrm{Xu}$ WG: Blockade of Notch signalling by $\gamma$-secretase inhibitor in lung $\mathrm{T}$ cells of asthmatic mice affects $\mathrm{T}$ cell differentiation and pulmonary inflammation. Inflammation 38: 1281-1288, 2015.

22. Shin YS, Takeda K and Gelfand EW: Understanding asthma using animal models. Allergy Asthma Immunol Res 1: 10-18, 2009.

23. Trifilieff A, El-Hashim A and Bertrand C: Time course of inflammatory and remodeling events in a murine model of asthma: Effect of steroid treatment. Am J Physiol Lung Cell Mol Physiol 279: L1120-L1128, 2000.

24. Bosire EM, Nyamache AK, Gicheru MM, Khamadi SA, Lihana RW and Okoth V: Population specific reference ranges of CD3, CD4 and CD8 lymphocyte subsets among healthy Kenyans. AIDS Res Ther 10: 24, 2013.

25. Larché M, Robinson DS and Kay AB: The role of T lymphocytes in the pathogenesis of asthma. J Allergy Clin Immunol 111: 450-464, 2003

26. Barnes PJ: Immunology of asthma and chronic obstructive pulmonary disease. Nat Rev Immunol 8: 183-192, 2008.

27. Massoud AH, Charbonnier LM, Lopez D, Pellegrini M, Phipatanakul W and Chatila TA: An asthma-associated IL4R variant exacerbates airway inflammation by promoting conversion of regulatory $\mathrm{T}$ cells to TH17-like cells. Nat Med 22: 1013-1022, 2016.

28. Tao B, Ruan G, Wang D, Li Y, Wang Z and Yin G: Imbalance of peripheral Th17 and regulatory $\mathrm{T}$ cells in children with allergic rhinitis AND bronchial asthma. Iran J Allergy Asthma Immunol 14: 273-279, 2015.

29. Tian M, Wang Y, Lu Y, Jiang YH and Zhao DY: Effects of sublingual immunotherapy for dermatophagoides farinae on Th17 cells and CD4(+) CD25(+) regulatory T cells in peripheral blood of children with allergic asthma. Int Forum Allergy Rhinol 4: 371-375, 2014.

30. Ma C, Ma Z, Fu Q and Ma S: Curcumin attenuates allergic airway inflammation by regulation of CD4+ CD25+ regulatory T cells (Tregs)/Th17 balance in ovalbumin-sensitized mice. Fitoter 87: 57-64, 2013.

31. Boyce JA and Austen KF: No audible wheezing: Nuggets and conundrums from mouse asthma models. J Exp Med 201: 1869-1873, 2005. 
32. Nials AT and Uddin S: Mouse models of allergic asthma: Acute and chronic allergen challenge. Dis Models Mech 1: 213-220, 2008.

33. Ming M, Luo Z, Lv S, Sun Q and Li C: Inactivated Mycobacterium phlei inhalation ameliorates allergic asthma through modulating the balance of CD4+CD25+ regulatory T and Th17 cells in mice. Iran J Basic Med Sci 19: 953-959, 2016.

34. Deckers J, Branco Madeira F and Hammad H: Innate immune cells in asthma. Trends Immunol 34: 540-547, 2013.

35. Stone KD, Prussin C and Metcalfe DD: IgE, mast cells, basophils, and eosinophils. J Allergy Clin Immunol 125 (2 Suppl 2): S73-S80, 2010.

36. Bandeira-Melo C, Bozza PT and Weller PF: The cellular biology of eosinophil eicosanoid formation and function. J Allergy Clin Immunol 109: 393-400, 2002.

37. Monteseirín J: Neutrophils and asthma. J Investig Allergol Clin Immunol 19: 340-354, 2009

38. Nabe T, Hosokawa F, Matsuya K, Morishita T, Ikedo A, Fujii M, Mizutani N, Yoshino S and Chaplin DD: Important role of neutrophils in the late asthmatic response in mice. Life Sci 88: 1127-1135, 2011.

39. Busse WW and Lemanske RF Jr: Asthma. New Eng J Med 344: 350-362, 2001.

40. Hwang SS, Kim YU, Lee S, Jang SW, Kim MK, Koh BH, Lee W, Kim J, Souabni A, Busslinger M and Lee GR: Transcription factor YY1 is essential for regulation of the Th2 cytokine locus and for Th2 cell differentiation. Proc Natl Acad Sci USA 110: 276-281, 2013.

41. Lambrecht BN and Hammad $\mathrm{H}$ : The immunology of asthma. Nat Immunol 16: 45-56, 2015

42. Wills-Karp M: Interleukin-13 in asthma pathogenesis. Immunol Rev 202: 175-190, 2004.

43. Brightling C, Saha S and Hollins F: Interleukin-13: Prospects for new treatments. Clin Exp Allergy 40: 42-49, 2010.

44. Desai D and Brightling C: Cytokine and anti-cytokine therapy in asthma: Ready for the clinic? Clin Exp Immunol 158: 10-19, 2009.
45. Fatemi F, Sadroddiny E, Gheibi A, Mohammadi Farsani T and Kardar GA: Biomolecular markers in assessment and treatment of asthma. Respirology 19: 514-523, 2014.

46. Holgate ST: Innate and adaptive immune responses in asthma. Nat Med 18: 673-683, 2012.

47. Gould HJ and Sutton BJ: IgE in allergy and asthma today. Nat Rev Immunol 8: 205-217, 2008.

48. Barnes PJ: The cytokine network in asthma and chronic obstructive pulmonary disease. J Clin Invest 118: 3546-3556, 2008.

49. Galli SJ, Grimbaldeston $M$ and Tsai M: Immunomodulatory mast cells: Negative, as well as positive, regulators of immunity. Nat Rev Immunol 8: 478-486, 2008.

50. Curtis JL, Warnock ML, Arraj SM and Kaltreider HB: Histologic analysis of an immune response in the lung parenchyma of mice. Angiopathy accompanies inflammatory cell influx. Am J Pathol 137: 689-699, 1990.

51. Jin H, Luo Q, Zheng Y, Nurahmat M, Wu J, Li B, Lv Y, Wang G, Duan $\mathrm{X}$ and Dong J: CD4+CD25+Foxp3+ T cells contribute to the antiasthmatic effects of Astragalus membranaceus extract in a rat model of asthma. Int Immunopharmacol 15: 42-49, 2013.

52. Amorim J, de Calvalho Borges M, Fabro AT, Contini SHT, Valdevite M, Pereira AMS and Carmona F: The ethanolic extract from Erythrina mulungu Benth. flowers attenuates allergic airway inflammation and hyperresponsiveness in a murine model of asthma. J Ethnopharmacol: Aug 10, 2018 (Epub ahead of print)

53. Kraft M: The distal airways: Are they important in asthma? Eur Respir J 14: 1403-1417, 1999.

54. Kraft M, Martin RJ, Wilson S, Djukanovic R and Holgate ST: Lymphocyte and eosinophil influx into alveolar tissue in nocturnal asthma. Am J Respir Crit Care Med 159: 228-234, 1999.

55. Kelly EA, Houtman JJ and Jarjour NN: Inflammatory changes associated with circadian variation in pulmonary function in subjects with mild asthma. Clin Exp Allergy 34: 227-233, 2004. 